\title{
CHARACTERISTICS OF THE UNEMPLOYMENT IN THE REPUBLIC OF MACEDONIA
}

\author{
Biljana Apostolovska Toshevska*, Blagoja Markoski, Olgica Dimitrovska, \\ Ivica Milevski, Svemir Gorin
}

Faculty for Natural Sciences and Mathematics, Institute of Geography, Skopje, Republic of Macedonia

\begin{abstract}
This paper focuses on the fact that Republic of Macedonia has faced for many years a high unemployment rate of over $30 \%$. The indications that average third of the unemployed are aged 25 to 34 years are alarming; almost half of the unemployed are without qualifications; and over $80 \%$ of the unemployed wait for employment for over 11 months. Obviously, these situations differ on a regional level, depending on the demographic and economic characteristics of the region. This paper emphasizes the need for further knowledge of the structural characteristics of the contingent of unemployed persons in Macedonia as a basis for further planning in the field of economy and non-economic sector, providing additional guidance in education, forming a strategy for equally regional economic and demographic development, which largely depends on the ability or inability of the person to be employed in some place.
\end{abstract}

Key words: Unemployment, Employment, Populations, Macedonia, Economic development

Article Info: Manuscript Received: December 15, 2011; Revised: May 5, 2012; Accepted: May 15, 2012; Online: May $29,2012$.

\section{Introduction}

The unemployment in the Republic of Macedonia is a major social, economic and political problem that has arisen from the occurrences inside and outside the boundaries of the state. The high rate of unemployment is characteristic for the entire period after declaring independence in 1991, although the unemployment was also high in the years before. In the course of the transition insufficient financial resources ensued, change in the model of economy, restructuring in the economy, change in the ownership structure, the conflict in 2001, all of which hampered with the solution or at least with the lowering of the rate of unemployment.

The unemployment has characteristics of involuntary unemployment "because the unemployed persons want to work, but there are no posts that according to the characteristics and salary offered are acceptable to them given their knowledge, skills and

\footnotetext{
* Corresponding author:

Address: Faculty for Natural Sciences and Mathematics

Institute of Geography, str. Gazi Baba b .b. 10oo Skopje, Republic

of Macedonia.

Telephone: 38923249999
}

Email: biljana.apostolovska@gmail.com qualifications" (Kandikijan et al., 2007) and also of structural unemployment for reason that positions are arising for which the unemployed have no qualifications to be employed (Risteski, 2010).

The unemployment with its characteristics, reasons and consequences has always been an interesting research for a number of authors, mostly sociologists, economists and geographers. In that context we cite researches on the dynamics and scope of unemployment (Risteski, 2005), the ratio of unemployment and GDP (Risteski, 2010), for the social transfers for unemployed persons (Trpeski, 2010), the economical aspect of the unemployment (Dieterich, 2006), etc.

The contents of the paper examine the problem from geographical aspect, highlighting the geographical aspects of the unemployment at a national and regional level.

\section{Methodology and data source}

Usually for unemployed persons are considered people who want to work, but cannot find a job. According to the International Labour Organization (ILO), a person is considered unemployed if it meets the following three conditions: during the reported 
week has not worked, actively looks for work i.e. has taken specific activities to find employment and is ready to accept offered work in the reported or the following week (Kandikijan et al., 2007) .

From the existing information which in the absolute sense represents the condition with the unemployment in the Republic of Macedonia, as most appropriate for processing are taken data from the Labour Force Survey from the State Statistical Office in the Republic of Macedonia (which is conducted on a random, representative sample), and the Employment Agency of the Republic of Macedonia (EARM). The EARM defines and considers the unemployment according the definitions provided and accepted by the Law on Employment and Insurance in case of Unemployment (Official Gazette 37/97 and 4/98), where for unemployed persons are considered persons that are registered in the Employment Office and are actively looking for employment in the previous two months. In terms of determining the duration of unemployment, the Standards for defining this phenomenon according to the ILO were used, where a long - term unemployment is considered an idle period over 1 year.

Unlike the data from the Labour Force Survey, in which the data for unemployed persons by municipalities are not present, the data from EARM follows the unemployment by municipalities, which is a solid base for regional geographical insight and analysis of this condition.

For reviewing the data by regions, it was worked according to the NUTS -3 classifications where eight statistical - planning regions were singled out. At the same time for preparation of the cartographic displays, the program package ARCGIS was used.

\section{Some characteristics of unemployment in the Republic of Macedonia}

In the whole analysed period (1996-2010), the absolute number of unemployed people notes oscillations, but it is evident that this in 2005 it reaches a peak with 323934 unemployed persons, or a third from the total workforce, despite the economic growth registered the same year. With a rate of unemployment of $32 \%$ in 2010, the Republic of Macedonia is among the European countries with highest unemployment rate far above the countries that were once together in the frames of former Yugoslavia, or almost four times the unemployment rate of the EU countries.

However, with these figures comes the need to comment the still present informal (grey) economy which obscures the real picture of employment. At the same time, an impact on the unemployment has the social transfers (Trpeski, 2010), also the changes in certain legal regulations (registration of the unemployed and regulation of the right of health care, the law for mandatory secondary education, etc.).

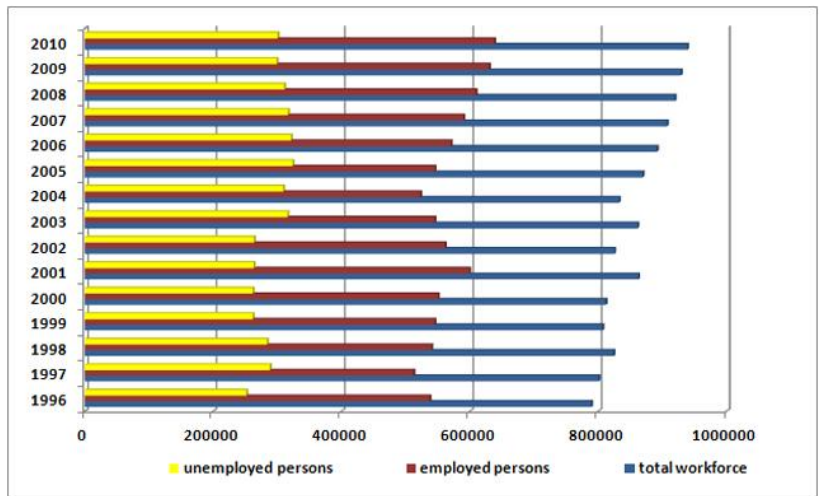

Figure 1. Correlation among workforce, employed and unemployed persons, 1996-2010

Data source: State Statistical Office in the Republic of Macedonia, Labor Force Survey 1996- 2010

The urban area, which at the same time absorbs most of the workforce, covers most of the unemployed persons. In average in the analysed period the unemployed persons in the city represent $31.6 \%$ of the total workforce in the urban areas or $58.4 \%$ from the total unemployed workforce in the country. These numbers are defeating and are unfavourable basis for the intention to renew life in the smaller urban areas. Even in Skopje, which as a bigger city is a place with a great number of commercial and non - commercial institutions seemingly offers more employment alternatives, faces expressed unemployment. Apart from Skopje, with high unemployment are faced the other major cities Kumanovo, Prilep, Bitola, Tetovo which in 2010 (together with Skopje) absorbed over half of the unemployed in the urban areas or nearly $40 \%$ from the total unemployed workforce. When from this number, the number of the persons employed but "victims" of the informal economy would be subtracted; this number of unemployed in the city would be smaller.

The average age of the unemployed in 2010 is 36.5 years (35,6 in rural areas and 37 in urban areas). Throughout the entire period, an average third of the unemployed persons are aged 25 to 34 years, and together with the persons from 35 to 44 , they account for half of the unemployed population in the country. The specified age period coincides with a series of activities related to the self - fulfilment and the self realization of an individual in terms of professional and personal level, where it is more than clear that the unemployment among this category of citizens is reflected on the overall demographic and social image in the country. That is, the unemployment and 
the difficulties of finding work and providing for an adequate standard of living are forcing people to marry later, delay births, and thus the size of families and the like (Daskalovski et al., 200o). The extension of the education process is certainly a mechanism for reducing of the unemployed persons aged 15 to 19 and from 20 to 24 years, although here the migration should not be neglected which for years had a positive migration balance from precisely this category of inhabitants of the Republic of Macedonia. Despite them, an increased participation is seen in people with over 44 years of age, especially from 55 to 64 years, where from 1996 to 2010 their share has increased from 6,6 to $11 \%$. This mass of unemployed largely comprises of persons in the category redundant and technological surpluses and which in recent years have been put in a situation where it's harder to find employment. On the other hand it is the result of market demand which mainly requires younger professional workforce.

Since one part of the young peasant population does not decide to continue their education, especially after secondary education, and because of migration flow to the urban centres and out of state, hence the higher share of this category in the total unemployed workforce. In contrast, the city has an older structure of unemployed persons with over 45 years of age that account for $30 \%$ of the total number of unemployed persons in the city, as we mentioned before is just a leftover from the period of restructuring in the economy.

In terms of age structure of unemployed persons by gender, in all the separated age groups most of the unemployed persons are men. Highlighted gender differences were recorded in the rural and the urban areas. Or two thirds from the unemployed in the rural areas are men, respectively $45 \%$ from the total unemployed male population in this country. From them, the biggest part is from 25 to 34 years of age. The unsolved question related to the unemployment is another problem that leads to worsening of the demographic balance in the area and enabling of equitable economic development. On the other hand,

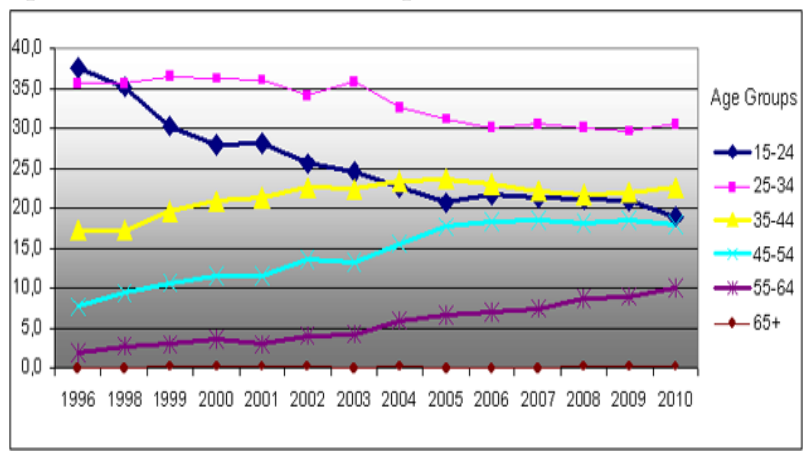

Figure 2. Structure of the age group among unemployed persons, (\%) 1996-2010

Data source: State Statistical Office in the Republic of Macedonia, Labor Force Survey 1996-2010

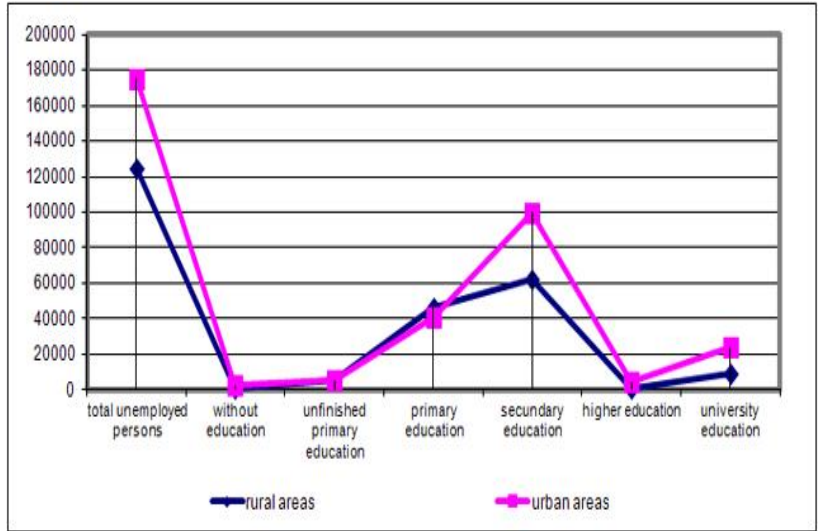

Figure 3. Unemployed persons by level of education, 2010 Data source: State Statistical Office in the Republic of Macedonia, Labor Force Survey, 2010

the observations directly from the geographical area indicate that the unemployment in large part of the rural population is not real; because in many rural areas, the involvement in the agriculture has no treatment of employment, so many individuals despite the revenue from agriculture, declare themselves as unemployed persons. Of course, the rural areas that are insufficiently economically developed and lack the basic conditions for living and working are excluded.

Almost $1 / 3$ of the unemployed persons have elementary education, and half have secondary education ( 3 or 4 years). In regard to the qualifications, $49 \%$ from the unemployed are unskilled. From them $29 \%$ are men, i.e. the half of the unemployed male workforce is without qualifications. According to EARM this category of unemployed in continuity participates with $1 / 3$ in the inflow in the number of registered unemployed persons, with little real employment opportunities. This is further aggravating factor for the reduction of the unemployment, because there are differences between the educational and professional characteristics of the unemployed and the demands of the labour market.

A reason for concern is the fact that in the unemployed without education the highest share is of persons from 25 to 34 years of age. If to this number we add the persons of the same age with incomplete or only primary education, it turns out that $28 \%$ of the people of this age are without or only with lowest level of education. Together with the unemployed persons from 15 to 24 years they comprise almost $40 \%$ from the unemployed persons with low educational characteristics. This is a defeating number for such a young population that really cannot incorporate in the labour market and surpass the poverty. Even $76.2 \%$ from the unemployed without education are in the urban areas or nearly half of the unemployed population without education and with unfinished and finished primary education is located in the 
cities. Also the urban environment absorbs a high per cent of the highly educated unemployed population. From the unemployed population a large share represent the unemployed with four years secondary education which in the present conditions of economic development have fewer employment opportunities. A concerning fact is that about $10 \%$ of the unemployed have a university education. It is a relatively young workforce that indicates a need of restructuring in the field of economy and the non economic sector and finding alternatives for its engagement.

The period of waiting for employment is more than alarming. Although it should be taken into account the educational structure, age, demand etc. the data indicate that $83 \%$ of the unemployed wait for employment for over 11 months, and $63.2 \%$ wait over 4 years. Among them most numerous (with 86\%) are persons with primary and secondary education. Even a third of the total unemployed with university

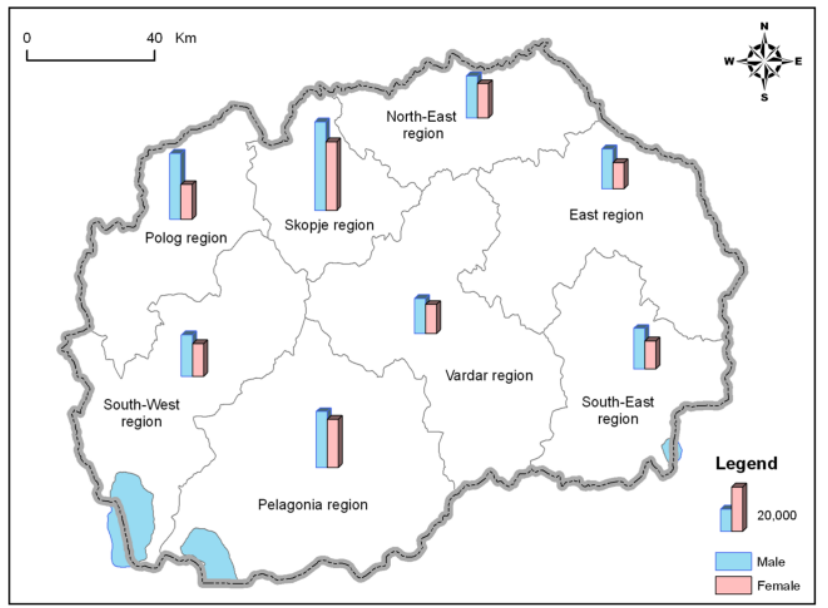

Figure 4. Unemployed persons in regions in Republic of Macedonia by gender, 2010

(According data from EARM)

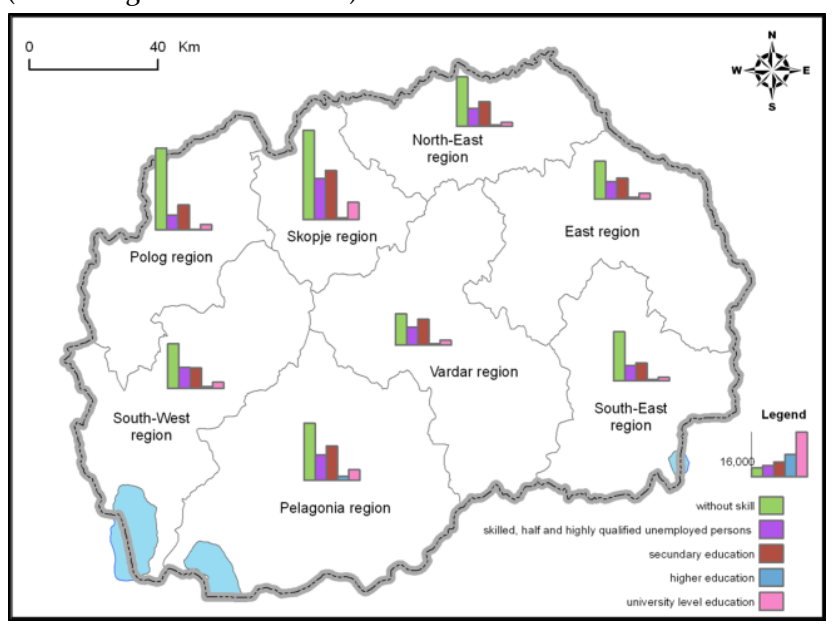

Figure 6. Unemployed persons in regions in Republic of Macedonia, by level of education 2010

(According data from EARM) education wait for employment longer than 4 years, which is largely due to inadequate politics in the production of personnel in the educational system according to the social needs (ApostolovskaToshevska et al., 2011).

In the long - term unemployed persons more numerous is the male population with participation of $61 \%$ that according the field findings is a result of the structure in the economy and the present sector of business where the female population has more opportunities for employment (textile industry, food processing industry, service sector, etc.), and also of several demographic characteristics. Over half of the persons with university education that wait for employment longer than 1 year are women. In general all the unemployed but educated persons that wait for employment for a longer period are also facing with other problems, such as loss of the already acquired knowledge that quickly becomes obsolete, and the loss of professional skills.

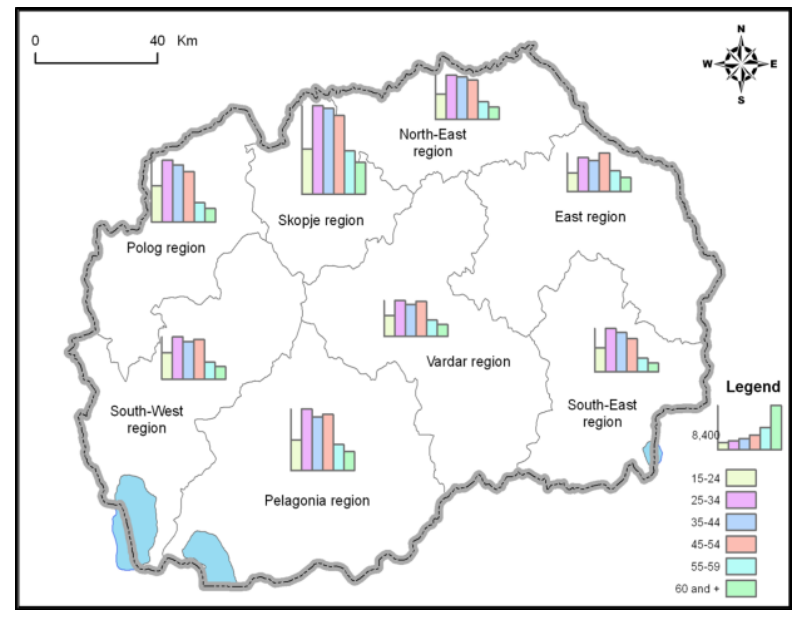

Figure 5. Unemployed persons in regions in Republic of Macedonia by age, 2010

(According data from EARM)

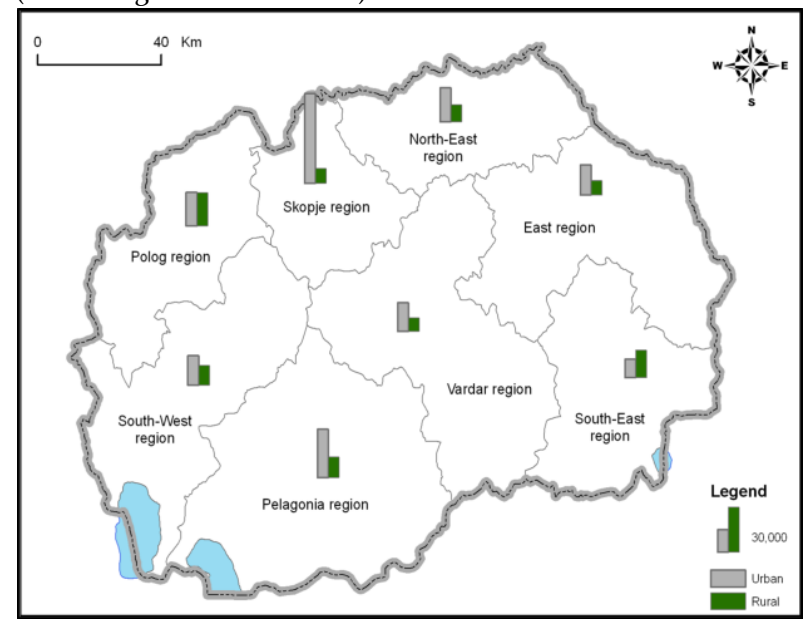

Figure 7. Unemployed persons in rural and urban areas in regions in Republic of Macedonia, 2010

(According data from EARM) 


\section{Unemployment regional disparities}

The unemployment in the Republic of Macedonia shows certain disparities at a regional level. This is mostly due to the economic structure, the level and potentials for development of the region. Some of these are characterized with great concentration of economic and non - economic objects, especially in the city centres and the immediate gravitational zone, which are attractive for migration of young unemployed people. The migrating flows from this kind are a reason for non-functional demographic polarization in the area, non - rational usage of the potentials and possibilities for development. In this regard the Skopje region especially stands out, this is the smallest region by surface area and covers only $7.3 \%$ from the territory of the Republic of Macedonia, officially $30 \%$ from the population lives here (only the city of Skopje absorbs $80 \%$ from the population in the region). At the same time, in this region one third from the total workforce is registered, and a rate of unemployment of 37.3 in 2008 (rate of employment 33.3 the same year).

As a result of the efforts for revitalization of the economy and stimulation of more economic sectors for development of the region in the field of industry (Apostolovska-Toshevska, Madzevic, 2009), agriculture and tourism, the South - East region (2008) shows highest rate of employment from 62.3 and lowest rate of unemployment of only 11.7, which is far below the rate on a national level. On the other hand, the North - East region, whose area is largely noted as insufficiently developed economic area, away from the investment flows and opportunities for demographic revitalization, has a rate of employment of only 25 and highest unemployment rate of 58 .

Besides the cited reasons for regional differences in the unemployment, big influence has the demographic characteristics. Namely, the size of the natural population growth (which in turn affects the age structure of the population and the influx of workforce), the ethnic and religious affiliation, which brings different cultural and living visions, different notion for the part of the genders, is of course reflected on the possibilities for mobility of the unemployed workforce and mass employment of the female population. In particular in regions where the prevailing population is the Albanian population or it is substantially present, a lower rate of activity is evident, primarily due to lower activity of the female population. Hence the Polog region manifests lowest rate of activity from 43.9 and a rate of unemployment of 26.4. In this context the Polog region shows lower involvement of the unemployed female persons in regard to the other regions. From the same reasons in the South - West, and especially in the Polog region there is a big discrepancy between the share of unemployed men and unemployed women with a longer period of waiting for employment.

In regard of the age structure of the unemployed persons, in all the regions the group of unemployed persons from 25 to 54 years participates with $2 / 3$. The older structure of unemployed persons from 55 to 60 and over 60 years is mostly present among the unemployed population in the Skopje and the East region, and a minimum in the South - East and the Polog region.

In all regions non - qualified unemployed workforce prevails, with stressed two - thirds participation in the Polog region. However the Skopje region features greatest absorption of unemployed with all types of education and qualifications that is certainly a normal situation considering the great number of workforce.

In regard the duration of unemployment, in all the regions over $80 \%$ from the unemployed wait for employment for over 11 months that points to a high degree of long term unemployment. From these, half wait employment up to seven years, and 25 to $30 \%$ participate the persons with long term of unemployment for 8 and more years. At every separated category of unemployment the Skopje region participates with nearly $20 \%$, and only the South - East region notes such participation from the unemployed persons from 5 to 7 years.

About 2/3 from the unemployed are recorded in the urban areas. The unemployed in the cities are more numerous in all the regions, except in the South - East region where $60 \%$ of the unemployed are from the villages and at the same time there is a big participation of the unemployed persons from the villages in the total unemployed workforce in the Polog and the South - West regions. Also the Polog region absorbs a fifth of the total number of unemployed people in the villages in this country. Of course, as we pointed before in the text, there is an unreality with the unemployment at the rural population in the noted regions, especially known by their great agriculturally - geographical characteristics which offered and are maximally used for agriculture. The real image for unemployment is blurred precisely because of the non - registering of agriculture as a basis for providing a personal existence.

Nearly $29 \%$ of the unemployed persons in the urban areas are located in the Skopje region.

\section{Suggested measures to overcome unemployment}

To overcome the problem of unemployment, it is necessary to use a compound of several measures of microeconomic and macroeconomic policies. These 
measures should allow improvements in the labour market, strengthening the potentials for engaging the work capable population, dealing with informal economy, increase of the investments, adjustment of the educational personnel with the labour demands, opportunities for re - training of unemployed persons, systematic and continuous training and lending through the private sector for young people that have a desire for opening small and medium enterprises (especially in the agricultural sector), partnerships between the government bodies, civil society, educational institutions and private sector in terms of employing young people, tax incentives for opening small and medium enterprises, especially in the rural areas, etc.

The sectorial growth, strengthening of the entrepreneurship and increase of the number of small and medium enterprises, and the presence of particular employment policies that can give results are of exceptional importance. Of all the sectors, the industrial sector represents main carrier of the economic activity, i.e. the rise of the industrial production, especially in the traditional export sectors by which the country is recognized, such as the metal, foods, textile industry, the industry for production of building materials, the tobacco industry and others, can have a strong influence on the changes in the unemployment. The sectors agriculture and construction, especially the infrastructure construction can absorb a great deal of the unemployed. Also, the tourism, as a part of the service sector, has the role of a mover of the overall economic development, and consequently contributes for reduction of the unemployment (Apostolovska-Toshevska et al., 2011).

In recent years, the efforts for encouraging of self - employment of the unemployed persons and assistance in guiding and professional moulding primarily of young employees have exceptional importance. Simultaneously, the subsided assistance for intensifying and encouraging of the agriculture, giving concessions of state agricultural lands greatly contributes to reduction of the unemployment.

In order to find appropriate measures for overcoming of the unemployment, it is extremely important to follow the experiences acquired by other countries and implementation of different models and methods that lead towards improvement of the employment, support of all stakeholders, business centres, strengthening the capacities of the existing regional centres, etc.

\section{Conclusions}

The analysis of the characteristics of the unemployment in the Republic of Macedonia has clearly demonstrated its demographic characteristics and geographically - regional peculiarities.

The official high rate of unemployment from $32 \%$ in 2010 ranks the Republic of Macedonia between the countries with highest rate of unemployment in Europe. Thus it has difficulties in the socio economic development, realization of the individual and his integration in the social structures and of course it confronts the problem of poverty.

The Macedonian cities absorb the largest number of unemployed persons. Among these and the capital, as largest and economically and infrastructurally shaped city, is faced with expressed unemployment. The rural population, especially in areas that are singled out as economically undeveloped are exposed to the inability for employment of the small unemployed workforce present there, which is only an additional argument in the determination of the individual to leave the village.

The unemployed population is relatively young with an average age of 36.5 years. In average, about one third of the unemployed persons are from 25 to 34 years of age, and together with the persons from 35 to 44 years of age they comprise one half of the unemployed population in the country. Unemployed are mostly people with low level of education. Almost $1 / 3$ from the unemployed people have primary education, and half have secondary education. In regard to the qualifications, $49 \%$ from the unemployed are not qualified; from them $29 \%$ are men. Up to $83 \%$ from the unemployed persons wait for employment for over 11 months, and $63.2 \%$ wait over 4 years. Among these most numerous (with $86 \%)$ are the persons with primary and secondary education.

The unemployment has regional differences which form one side come from the opportunities for employment, the economic potential and growth of the region, while from the other side, major influences are the demographic characteristics, the national identity (always in correlation with the cultural and religious views), where there are difficulties in the labour mobility or is influenced by the treatment of the female population and their involvement in the community.

The analysis of the data of the unemployment in regions shows that in all regions the group of unemployed persons from 25 to 54 years participates with $2 / 3$. The older structure of unemployed persons from 55 to 60 and over 6o years is mostly present among the unemployed population in the Skopje and the East region, and a minimum in the South - East and the Polog region. Non - qualified unemployed workforce prevails, with stressed two - thirds participation in the Polog region. In all the regions over $80 \%$ from the unemployed wait for employment 
for over 11 months that point to a high degree of long term unemployment.

This perception of the characteristics of the unemployment in the Republic of Macedonia is only a basis for further strategic steps towards organizing all segments of the society, a basis for realization of investment plans, a key element for developing a strategy for economic, demographic and sustainable development.

\section{References}

Apostolovska-Toshevska, B \& Madzevic, M 2010, 'Labor force in Republic of Macedonia', Proceedings of the Forth congress of the geographies in Republic of Macedonia, 7-10. X. 2019, Dojran; (in Macedonian).

Apostolovska-Toshevska, B, Madzevic, M, Markoski, B, Dimitrovska, O, Milevski, I \& Gorin S 2011, 'Duration of unemployment in Republic of Macedonia', Proceedings from the Third Congres of Serbian geographers with international participation, Banja Luka, (in Serbian)

Baletic, AW 1973, (ed), Demography of the population and economic development, Zagreb.

Daskalovski, V, Madzevic, M \& Apostolovska-Tosevska, B 200o, 'Changes in the 1990s and the Demographic Future of the Balkans', Socio-demographic characteristics of the female labor and the question of employment, International conference, DEMOBALK, 10-13 May, 2000, Saraevo.
Dieterich, $\mathrm{K}$ 2006, 'Unemployment in Republic of Macedonia', Gazette of the Ministry of Finance, www.finance.gov.mk

Employment Agency of the Republic of Macedonia, www.avrm.gov.mk

Government of the Republic of Macedonia, Ministry of Labor and Social Policy, 2008, Strategy for demographic development in Republic of Macedonia 2008-2015, (in Macedonian) www.mtsp.gov.mk

Kandikijan, V \& Grozdanovski, T 2007, Economic, Iustinianus Primus Faculty of Law, Skopje (in Macedonian)

Madzevic, M \& Apostolovska-Toshevska, B 2009, 'Correlation between industrialization and urbanization in Republic of Macedonia', Proceedings of the International symposium Geography and sustainable development, 22-25. 10. 2009, Ohrid (in Macedonian),

Risteski, S 2005, 'Unemployment in Republic of Macedonia (dynamic, characteristics and measures to reduce)', Proceedings of the International conference Modern trends and policies in structural changes in the economy, Faculty for Economy, Skopje (in Macedonian)

Risteski, S 2010, 'Dinamic of GDP and employment in Republic of Macedonia (confusion about the grow)', Annual of Economic Faculty, v. 25, Skopje (in Macedonian)

State Statistical Office in the Republic of Macedonia, Labor Force Survey from 1996 to 2010, www.stat.gov.mk

Trpeski, P 2010, 'Social transfers for unemployed persons in Republic of Macedonia and implication to the labor market', Annual of Economic Faculty, v. 25, Skopje (in Macedonian) 